\title{
CLINICAL PROFILE AND MANAGEMENT OF GALL BLADDER CANCER: OUR EARLY EXPERIENCE
}

\author{
Sujit Kumar, Prakash Kafle, N Maharjan, BN Patowar, \\ $N$ Belbase, SJ Shrestha, S Agrawal
}

\begin{abstract}
Objective: To evaluate the clinical profile of patients with gallbladder cancer.

Methodology: This is a single institution based retrospective study of patients with gallbladder cancer who presented at College of Medical Sciences and Teaching Hospital, Bharatpur, Chitwan, Nepal. Patients presenting during the two years period from August 2011 to July 2013 were reviewed.
\end{abstract}

Result: Out of 12 patients, 9 were females (75\%) and 3 were males (25\%), showing female preponderance. Most of the patients (75\%) were in age group of 51-70 years. Only one patient $(8 \%)$ was below 50 years of age. Main symptom was pain associated with anorexia, nausea \& vomiting. Major signs were palpable mass, hepatomegaly and jaundice. All the histopathological reports were adenocarcinoma. 8 patients $(66.66 \%)$ presented with advanced disease and were managed with extended cholecystectomy followed by systemic chemotherapy.

Conclusions: Prevalence of gall bladder cancer is higher in females in our series. Most of the patients were in fifth to seventh decade of life and presented in advanced stage. Gallbladder cancer showed association with gallstones.

Key Words: Gallbladder cancer, extended cholecystectomy, cholelithiasis.

\section{Introduction}

Carcinoma of the gallbladder (GBC) is the most frequent malignant tumor of the biliary tract and the fifth most common cancer of the digestive tract. Gallblader cancer is an aggressive malignancy and caries extremely poor prognosis. Patients commonly present in late stage as it have no disease specific presenting symptoms. Have no specific presenting symptoms and therefore presentation with late - stage disease is common. In the United States and Europeans countries, GBC is an uncommon tumor accounting for less than $2 \%$ of all cancer reported annually. However, 6000 to 7000 new cases are reported annually in the United States. Ethnicity plays an important role in the development of GBC with highest incidence in the women population from India and Pakistan. Among North American populations, Native Americans and immigrants from Latin America have the highest rate. The reasons for these geographical or ethnic variations for biliary tract cancer are not clear, but some unknown environmental risk factors or a genetic susceptibility are suspected. Most of the patients reported are female over 50 years of age and with concomitant gall stone. Presence of gallbladder stone is considered as the primary risk factor and larger stone $(>3 \mathrm{~cm})$ 
carry an increased risk of cancer development. It is 7 times more common in patients with cholelithiasis. The risk of gallbladder cancer increases with certain risk factors like abnormal pancreaticobiliary junction (APBJ), choledochal cyst, primary sclerosing cholangitis (PSC), porcelain gallbladder and GB polyps larger than 10 $\mathrm{mm}$.

Other factors that are associated with GBC are pregnancy, female sex hormones, low fiber, vitamin A intake and high fat intake. There may be an association between chronic typhoid infections and subsequent development of gallbladder cancer and the likelihood of such a progression is six times higher than in normal subjects. The commonest histological type is adenocarcinoma. This may be glandular, medullary, scirrhous, papillary or colloid. It appears that papillary forms have a better prognosis than the nodular infiltrate form. Occasionally, undifferentiated carcinoma, squamous cell carcinoma, carcinoma in situ and a mixed group of rarities are reported. Very rarely, malignancy may develop from non-papillary adenomas, especially large ones over one centimeter in diameter.

The purpose of conducting this study was to evaluate the clinical profile of patients presenting to us and subsequently diagnosed with GBC.

\section{Methodology}

\section{Patient and Study design}

This is a retrospective study conducted at College of Medical Science and Teaching Hospital (COMS-TH), Bharatpur, Nepal after the approval from the ethical committee. Data were collected from the OT register and medical record files. There were total 12 cases of GBC admitted in between August 2011 and July 2013. Each patient's record was examined carefully to obtain the following data: age, sex, duration of symptom, presenting symptoms and signs, type of operative procedure, operative findings, presence or absence of stones in gallbladder, histopathology of the resected specimen, perioperative complications and adjunctive therapy.

\section{Results}

The mean age in the study was between 51-70 years. Nine out of the total 12 patients comprising $75 \%$ were females and $25 \%$ $(n=3)$ were males. Age and sex distribution of these patients is given in Table-I.

Table 1. Age and Sex distribution of study population.

\begin{tabular}{|l|l|l|l|}
\hline \multicolumn{1}{|c|}{ Age } & Male & Female & $\begin{array}{c}\text { Total } \\
\text { Percentage } \\
(\mathbf{\%})\end{array}$ \\
\hline$<50$ & 1 & 1 & $16.66(\mathrm{n}=2)$ \\
\hline $51-70$ & 1 & 7 & $66.66(\mathrm{n}=8)$ \\
\hline$>70$ & 1 & 1 & $16.66(\mathrm{n}=2)$ \\
\hline Total & 3 & 9 & $100 \%$ \\
\hline
\end{tabular}

Table 2. Clinical presentation

\begin{tabular}{|c|c|c|}
\hline SN & Symptoms & $\begin{array}{c}\text { Percentage } \\
(\%)\end{array}$ \\
\hline 1 & $\begin{array}{lr}\text { Non-specific } & \text { chronic } \\
\text { abdominal } & \text { pain, } \\
\text { nausea,vomiting } & \\
\end{array}$ & 58.33 \\
\hline 2 & $\begin{array}{l}\text { Early satiety, abdominal } \\
\text { fullness, anorexia }\end{array}$ & 16.66 \\
\hline 3 & Jaundice & 16.66 \\
\hline \multirow[t]{3}{*}{4} & Weight loss, pruritus & 8.33 \\
\hline & Total & 100 \\
\hline & Signs & \\
\hline 1 & $\begin{array}{l}\text { Palpable RUQ mass } \\
\text { with hepatomegaly }\end{array}$ & 58.33 \\
\hline 2 & $\begin{array}{ll}\text { Emaciation } & \text { and } \\
\text { Cachexia } & \end{array}$ & 16.66 \\
\hline 3 & $\begin{array}{l}\text { Ascites and peripheral } \\
\text { edema }\end{array}$ & 16.66 \\
\hline \multirow[t]{2}{*}{4} & Acute cholecystitis & 8.33 \\
\hline & Total & 100 \\
\hline
\end{tabular}


Mean duration of presentation was variable which ranged from 2 days to 10 years. Patient presenting with the features of acute cholecystitis that underwent cholecystectomy and histopathologically diagnosed as GBC was the one who presented with the shortest duration of symptom. Among the remaining cases, majority of the patients presented with the symptoms like chronic epigastric pain, nausea and vomiting comprising 58.33\% $(n=7)$ while early satiety, sense of fullness and anorexia was present in $16.66 \%$ and $16.66 \%$ presented with jaundice. Weight loss, abdominal distention and pruritus were associated with the late stage of the disease which was observed in $8.33 \%$. Palpable right upper quadrant mass and hepatomegaly were present in $58.33 \%$ of the patients which was the major sign in our study. Of the study population, $16.66 \%$ presented with emaciation and cachexia while ascites and peripheral edema was seen in two patients (16.66\%). Remaining $8.33 \%$ presented with features of acute cholecystitis. Imaging modalities, mainly USG, revealed gallstones in $75 \%(n=9)$ and gallbladder mass in $25 \%$ $(n=3)$. Extended cholecystectomy was performed in 5 cases and completion extended cholecystectomy was done in 1 case who had undergone open cholecystectomy for acute cholecystitis, while 6 out of the 12 cases were inoperable. Systemic chemotherapy was initiated in all of the 12 patients. The histopathology report of the 6 resected specimens confirmed adenocarcinoma of gallbladder. The rest of the patients who were designated as inoperable by CT scan of abdomen and pelvis were diagnosed to have GBC on the basis of USG guided tissue biopsy. The intra-operative findings seen in the study population is demonstrated in the Table-III. There was no significant perioperative complications noted.
Table 3. Intraoperative findings $(\mathbf{n}=\mathbf{6})$

\begin{tabular}{|l|l|l|}
\hline S.N. & \multicolumn{1}{|c|}{ Findings } & \multicolumn{1}{|c|}{$\begin{array}{c}\text { Percentage } \\
\mathbf{( \% )}\end{array}$} \\
\hline 1 & $\begin{array}{l}\text { Pericystic LN } \\
\text { involvement. }\end{array}$ & $33.33(\mathrm{n}=2)$ \\
\hline 2 & $\begin{array}{l}\text { Liver metastases } \\
\text { (including } \\
\text { completion extended } \\
\text { cholecystectomy) }\end{array}$ & t9.99(n=3) \\
\hline 3 & $\begin{array}{l}\text { Limited } \\
\text { gallbladder }\end{array}$ & $16.66(\mathrm{n}=1)$ \\
\hline
\end{tabular}

LN=Lymph Node

\section{Discussion}

In our study, GBC was predominant in female with the ratio of $3: 1(\mathrm{~F}: \mathrm{M})$ and is similar to the findings as reported in by Patrick $\mathrm{G}$ et al. Most of the patient in our study were in the age group of 51-70 years. This data is consistent with the data in different literature where it has been found that in more than 75 $\%$ of the cases of the GBC mean age was more than 65 years. Because $90 \%$ of gallbladder cancer originate in the fundus or body, they don't produce symptoms until the disease is advanced. In our series, $58.33 \%$ of population presented with nonspecific symptoms like abdominal pain, nausea and vomiting. Mirsa $\mathrm{S}$ et al has also mentioned that due to the nonspecific symptoms and signs, establishing a proper diagnosis is difficult in case of gallbladder carcinoma. In our series, association of gallstone with gallbladder cancer was found in $75 \%$ while Marcus CB has shown that $95 \%$ of the cases with GBC have gallstones. The histopathological report in Kyriacou E revealed adenocarcinoma of gallbladder and similar result was seen in our study too. Resection of the gallbladder cancer remains the only potential for cure. Patients are divided into four specific sub-group of presentation - patient with an incidental polyps on imaging, patient with an incidental finding of gallbladder cancer at time of or 
following cholecystectomy, patients suspected of having gallbladder cancer preoperatively and patients with advanced disease at presentation. For polyp and gallbladder cancer following cholecystectomy with T1a \& b, simple cholecystectomy is sufficient as long as the margins are negative. However, the perilymphatic and vascular invasion is high with the T1b stage so extended cholecystectomy directed at obtaining R0 resection with excision of draining lymph node is the treatment of choice. For T2, T3 and T4 stages, radical cholecystectomy is indicated. Debulking without possibility of complete resection has no role in the management of gallbladder cancer. When disease is too advanced, only palliative procedures are done. In our study, extended cholecystectomy was done in all the operated cases $(n=6)$ and followed by oral gemcitabine. Most of the patients were discharged with the mean duration of hospital stay of 10 days ranging from 7 to 20 days.

\section{Conclusion}

Gallbladder is a rare identity with silent progression thus present in advanced stage carrying high rate of mortality and morbidity. It is more common in female than in male. Presence of gallstone has higher risk of malignancy. Therefore, early cholecystectomy for cholelithiasis is the best way to prevent gallbladder cancer to some extent. Different literatures suggest that overall survival of the gallbladder cancer is less than $15 \%$ with median survival of 13 months in metastatic disease. The five year survival couldn't be commented on this study because of short duration of follow up and the timing of study performed.

\section{$\underline{\text { References }}$}

1. Patrik GJ and Steven RTE. Biliary System. In: Townsend CM, Beauchamp RD, Evers BM et al, editors. Sabiston Text Book of Surgery The Biological Basis of Modern Surgical Practice. 19th ed. Philadelphia:Elsevier Saunders. 2012;1476514.

2. Misra S, Chaturvedi A, Misra NC. Gallbladder cancer. Curr Treat Options Gastroenterol. 2006;9:95-106.

3. Greenlee RT, Hill-Harmon MB, Murray T, Thun M. Cancer statistics, 2001. CA Cancer J Clin. 2001;51:15-36.

4. Malik IA. Gallbladder cancer: current status. Expert Opin Pharmacother. 2004;5:1271-7.

5. Ahmad M, Khan AH, Mansoor A. The pattern of malignant tumours in northern Pakistan. J Pak Med Assoc. 1991;41:270-3.

6. Rizvi TJ, Zuberi SJ. Risk factors for gall bladder cancer in Karachi. J Ayub Med Coll Abbottabad. 2003;15:16-8.

7. Welton JC, Marr JS, Friedman SM. Association between hepatobiliary cancer and typhoid carrier state. Lancet. 1979;1:791-4.

8. Carriaga MT, Henson DE. Liver, gallbladder, extrahepatic bile ducts, and pancreas. Cancer. 1995;75:171-90.

9. Ravi SC, Simul AS. Biliary System. In: Townsend CM, Beauchamp RD, Evers BM et al, editors. Sabiston Text Book of Surgery The Biological Basis of Modern Surgical Practice. 18th ed. Philadelphia:Elsevier Saunders.2008;1547-87.

10. Misra S, Chaturvedi A, Misra NC, Sharma ID. Carcinoma of the gallbladder. Lancet Oncol. 2003;4:167-76.

11. Marcus CB,tand and Steven M,Strasberg. Biliary Surgery. In: Mary EK, Abdulhameed A, Ankit B, Amy CF, Matthew RP. editors. Washington Manual TM of Surgery. 6th ed. New Delhi; Walters Kluwer.2012;363-86.

12. Kyriacou E. Carcinoma of the gall-bladder. J Gastroenterol Hepatol. 1999 Mar;14(3):215-9.

Correspondence Address: Dr. Sujit Kumar drsujit17550@gmail.com Or Dr.Prakash Kafle prakashkaflee@hotmail.com 